\title{
Criminalização, racialização e patologização: as origens do sistema de justiça juvenil da Califórnia
}

\author{
Criminalization, racialization and pathologization: the origins of the juvenile \\ justice system in California
}

\section{Eduardo Gutierrez Cornelius ${ }^{\mathrm{a}}$}

Chávez-García, Miroslava. States of Delinquency: Race and Science in the Making of California's Juvenile Justice System. Los Angeles: University of California Press, 2012.

Nos Estados Unidos, negros e latinos constituem a maior parte dos jovens no sistema de justiça juvenil, embora sejam minoria na população do país. Pertencentes a esse grupo possuem uma chance muito maior de serem presos, receberem sentenças mais longas e serem julgados como adultos. Partindo desse diagnóstico atual, Estados de delinquência: raça e ciência na constituição da justiça juvenil da Califórnia reconstrói as origens da relação entre raça e justiça juvenil no mais rico e populoso estado americano. Nessa obra, a historiadora Miroslava Chávez-García expõe como ideias e práticas que alavancaram a formação da justiça juvenil no estado californiano serviram para patologizar, segregar e esterilizar jovens considerados problemáticos, sobretudo os pertencentes a minorias raciais.

A Escola de Whittier e a Escola Industrial de Preston constituem o cenário de Estados de Delinquência. O foco nessas escolas de reforma - como ficaram conhecidas nos Estados Unidos - permite à autora analisar o contexto social e as ideias que impulsionaram a formação da justiça juvenil no final do século XIX, bem como as práticas a que foram submetidos milhares de jovens e os episódios que marcaram a reorganização da justiça juvenil na década de 1940: os suicídios de dois jovens de origem mexicana em Whittier.

A partir da análise de cerca de 8.000 prontuários de internos, relatórios de avaliações sociais, reportagens de jornais, dados quantitativos e histórias orais, Chávez-García descreve minuciosamente as experiências dos jovens submetidos ao sistema de justiça juvenil. Cada um dos seis capítulos da obra carrega o nome de um ou mais personagens cujas histórias pessoais são utilizadas para ilustrar eventos mais amplos. Apesar de pouco analítica, a autora realiza uma descrição

a Mestrando no Programa de Pós-Graduação em Sociologia da Universidade de São Paulo. 
minuciosa das práticas punitivas direcionadas à juventude. Assim, Estados de Delinquência auxilia a compreender permanências e descontinuidades no controle de jovens da atualidade, tanto nos Estados Unidos, quanto no Brasil, país em que há poucos trabalhos sobre a formação da justiça juvenil e a experiência de jovens de minorias raciais a ela submetidos.

No Capítulo 1, a autora utiliza a história de Arthur C., um americano de ascendência mexicana, para ilustrar as transformações na forma como o Estado da Califórnia lidou com adolescentes vistos como problemáticos a partir da metade do século XIX. Após a anexação do território da Califórnia pelos Estados Unidos em 1848, abordagens centradas na família e na comunidade cederam espaço a um sistema estatal de controle de jovens indisciplinados. Com a conquista estadunidense e com a descoberta de minas de ouro na Califórnia, grandes quantidades de euro-americanos e europeus migraram para o estado, modificando a configuração social californiana.

Assim como no Brasil (Alvarez, 1990), formou-se nos Estados Unidos um movimento reformador de salvação da infância. Esse movimento estava particularmente preocupado com o aumento da população de jovens "incontroláveis" e em situações de necessidade nas ruas. Assim, novas organizações surgiram, como a Sociedade de Ajuda a Meninos e Meninas, em 1868, e a Sociedade para a Prevenção da Crueldade Contra Crianças, em 1876. A essa época, questões relativas à punição, como administração de prisões, prevenção de crimes e tratamento de presos penetraram o cenário político da Califórnia. Dessa forma, em 1884, legisladores apontaram uma comissão para encontrar estratégias estatais para lidar com os jovens indesejados. A comissão recomendou que a Califórnia desenvolvesse um programa centrado na disciplina, educação e trabalho dos jovens, que deveriam ser colocados em um ambiente familiar separados por idade, sexo e características pessoais. Desse modo, a autora demonstra como o surgimento da justiça juvenil californiana - assim como no Brasil (Alvarez, 1990) - esteve estreitamente vinculado a uma preocupação com a juventude pobre urbana, que deveria ser reformada pelo Estado.

Nos três capítulos seguintes, Chávez-García expõe como as práticas de reforma dos jovens pautaram-se por ideias científicas da época - notadamente a eugenia em uma parceria entre Universidade e instituições correcionais. Assim, a autora demonstra como essa abordagem científica diferenciou jovens recuperáveis de não recuperáveis a partir da aplicação de testes de inteligência e de avaliações holísticas baseadas em concepções de superioridade de brancos e inferioridade de outros grupos raciais. 
O Capítulo 2, intitulado "Fred C. Nelles. Reformista Inovador, Eugenista Conservador", demonstra como o diretor da Escola de Whittier entre 1912 e 1927 esforçou-se para estabelecer um programa progressista e científico para salvar os jovens californianos. Nelles buscou transformar a Escola, que funcionava sob uma lógica de disciplina militar, em um ambiente familiar. Uma de suas primeiras medidas foi a de acabar com castigos físicos. A Escola de Whittier, embora fundada em 1889 como uma alternativa à prisão, era palco de inúmeros castigos corporais. Com a orientação ou, no mínimo, a conivência da administração, guardas mal pagos e mal preparados utilizavam técnicas como a de amarrar jovens a postes e açoitá-los, colocá-los em confinamento solitário e deixá-los pendurados por algemas nos pulsos até que desmaiassem. Além de proibir essas práticas, Nelles acabou com o sistema de recrutamento de jovens mais velhos, a quem a administração conferia certa autoridade perante os demais internos, o que gerava situações de violência física e sexual.

No lugar dessas práticas, Nelles criou um sistema baseado na confiança de que os jovens cumpririam as normas. Caso isso não ocorresse, eles eram transferidos para uma unidade com menos benefícios. Assim, jovens que não obedecessem às regras poderiam ser alimentados apenas com pão e água, proibidos de conversar com outros internos ou serem obrigados a realizar tarefas específicas. Desse modo, Chávez-García demonstra que a nova abordagem estatal frente aos jovens delinquentes e abandonados não significou meramente a transição para uma punição mais leniente, mas sim para uma forma de punir distinta: "não punir menos, mas punir melhor" (FouCAUlt, 2011, p.79).

O programa de Nelles envolvia também a separação de adolescentes de acordo com suas características individuais. Para tanto, o diretor esforçou-se para enviar jovens cujas características revelassem inaptidão para a reabilitação a outras instituições. Além disso, Nelles contribuiu para a promulgação de uma lei permitindo o ingresso na Whittier de jovens de até 15 anos, já que os mais velhos eram considerados de difícil correção.

Membro da Academia de Criminologia do Sul da Califórnia, Nelles era um grande entusiasta da utilização da ciência para resolver problemas sociais. Assim, foi bem-sucedido em defender a criação do Escritório de Pesquisas Juvenis da Califórnia dentro da escola Whittier, conduzido por um psicólogo da Universidade de Stanford. É interessante observar que instituições como essa também foram construídas no Brasil, como o Laboratório de Biologia Infantil estabelecido no Rio de Janeiro e o Instituto de Pesquisas Juvenis, em São Paulo (cf. Bernal, 2004). Além de realizar pesquisas sobre a delinquência juvenil, os trabalhadores do instituto californiano aplicavam um teste de QI aos internos da escola, utilizando uma 
escala que apresentava sete níveis, que iam desde "superior" até "idiota”. O objetivo era identificar quais jovens eram passíveis de recuperação e quais deveriam ser enviados a outras instituições para reclusão e esterilização.

Chávez-García explica que os pesquisadores chegaram à conclusão de que, em comparação com jovens não criminosos, jovens "delinquentes" apresentavam um QI bastante inferior. Igualmente, concluíram que jovens brancos apresentavam, em média, um "atraso mental" muito menor do que o de adolescentes pertencentes a minorias raciais, como negros e mexicanos. Como consequência, jovens pertencentes a minorias raciais tornaram-se raros em Whittier, já que Nelles os enviava para outras instituições. Em complemento à aplicação dos testes de QI, o instituto contava com "avaliadores eugenistas". Para abordar o trabalho desse grupo, Chávez-García recorre à figura de Mildred Covert, que dá nome ao Capítulo 3. Covert, juntamente com seus colegas, entrevistou jovens e suas famílias com o objetivo de desvendar as causas hereditárias e ambientais de seu comportamento delinquente e de prever suas possibilidades de vida futura, baseando-se na eugenia.

A eugenia como um campo científico foi desenvolvida no final do século XIX. Inspirada em teorias biológicas como o Lamarckismo, segundo a qual o ambiente é capaz de moldar as características que um indivíduo passa a sua prole, a eugenia consistia na ideia de que a condição humana poderia ser melhorada prevenindo-se a transmissão de características tidas como inferiores. No Brasil, ideais eugênicos foram amplamente difundidos, inclusive no campo da punição. Como demonstra Alvarez (2003), ideias da escola italiana positivista influenciaram médicos ejuristas que objetivavam reformar as leis penais no país, as quais deveriam se adequar a diferenças raciais. Nos Estados Unidos, teorias eugênicas foram defendidas por Charles Davenport, professor de Mildred Covert - na Universidade de Chicago - e criador do Escritório de Registros Eugênicos em 1910. A demanda por avaliações de pacientes e presos era tão grande que Davenport criou um curso de seis semanas para treinamento de "avaliadores eugenistas". Nesse curso, ensinavam-se antropologia, herança genética, origem de traços mentais e a aplicação de testes de QI. Em busca pelas causas da delinquência e na tentativa de prever o futuro dos jovens, os avaliadores entrevistavam adolescentes e suas famílias, investigando as características de seus parentes até a quarta geração, um trabalho semelhante ao levado a cabo na São Paulo do início do século XX (cf. BernaL, 2004).

O objetivo dos avaliadores era montar uma árvore genealógica, identificando os "defeitos" que os ascendentes poderiam ter passado a seus descendentes. Tais avaliadores buscavam por sinais de alcoolismo, imoralidade sexual, excitabilidade, apatia, nomadismo e crime. Questões como jeito de falar e de sorrir, receptividade, 
vocabulário e aparência eram avaliadas e associadas a traços biológicos. Quando não era possível entrevistar os familiares, os avaliadores recorriam a fotografias para concluir sobre os traços de personalidade dos pais dos jovens. Em um dos relatórios descritos por Chávez-García, uma avaliadora narra que apenas olhando para a fotografia da mãe de um jovem, concluiu que ela era uma mulher de "personalidade fraca”. Além disso, as casas e as vizinhanças das famílias dos jovens eram avaliadas, seguindo escalas padronizadas produzidas na Whittier. Essas escalas permitiam a atribuição de pontos (até cinco) para cinco categorias, avaliando aspectos como limpeza e tamanho da casa.

Conforme Chávez-García, as ideias pré-concebidas sobre os entrevistados ficavam claras nos relatórios dos avaliadores, que usavam expressões como "casa típica de negros" ou "casa surpreendentemente limpa para uma família mexicana", ou ainda "expressa [ao falar] os exageros típicos de sua raça" (p. 87). Embora considerações raciais sobre adolescentes brancos e suas famílias fossem raras, quando eram utilizadas revelavam o favorecimento dos avaliadores a esse grupo. Em um relatório sobre uma família de ascendência sueca, por exemplo, consta que seus membros eram "muito disciplinados, como era de se esperar de sua raça" (p. 90).

Nos testes de QI em que jovens não brancos atingiam resultados positivos, os avaliadores pareciam esforçar-se para explicar o comportamento criminoso dos jovens a partir de outros fatores. A autora narra que John, um menino negro internado em Whittier, atingiu o nível de QI mais alto já encontrado na escola. Ao entrevistá-lo, a eugenista Mildred Covert relatou que, embora o jovem tivesse apenas 12 anos, seu vocabulário era superior ao de universitários. Contudo, Covert relata ter percebido que John possuía uma "inércia racial" (p.89). Em suas recomendações sobre o futuro de adolescentes como John, os relatórios eram claros: executar trabalhos manuais simples. Como no Brasil (AlvAREZ, 1990), a conversão dos jovens indisciplinados em trabalhadores úteis estava no centro das preocupações dos reformadores californianos.

No Capítulo 4, Chávez-García revela como alguns jovens eram selecionados para passar por um processo de esterilização compulsória. Tal prática, defendida nos Estados Unidos por grupos como a Sociedade Americana de Eugenia e a Fundação de Melhoramento Humano, era destinada a promover "as qualidades raciais das gerações futuras” (p. 115). Na Califórnia, tal prática foi legalizada em 1909, e podia ser aplicada em casos de "doença mental que pode ter sido herdada e provavelmente será transmitida a descendentes” (p. 63). Contestada judicialmente, tal legislação teve sua legalidade reconhecida pela Suprema Corte, que afirmou sua utilidade no controle da reprodução de "imbecis". Como resultado, cerca de $\mathbf{2 0 . 0 0 0}$ esterilizações foram levadas a cabo na Califórnia, um terço das 
60.00o realizadas em todo o país, uma prática que só foi tornada ilegal em 1979 no estado. Novamente, embora a maioria das esterilizações fosse dirigida contra brancos - que formavam a grande maioria da população -, não brancos estavam desproporcionalmente representados entre as vítimas.

Apesar do grande número de esterilizações realizadas, Chávez-García observa que a maioria das vítimas de esterilização era composta por pacientes em instituições de saúde mental. Uma minoria, cerca de 126 jovens "delinquentes", foram esterilizados. O baixo número de adolescentes em comparação ao total de esterilizados é atribuído pela autora ao desdém do eugenista Fred Butler - responsável pelo hospital que conduzia o procedimento - por criminosos. Tendo conduzido o Hospital de Sonoma por mais de 30 anos, Butler considerava que adolescentes delinquentes eram de difícil controle. Desse modo, a maioria dos jovens identificados como "débeis mentais" em Whittier eram enviados à Escola de Preston.

Esses três capítulos demonstram como saberes científicos articularam-se nas práticas de reforma dos jovens californianos. No Brasil, apesar de não terem sido promulgadas leis permitindo a esterilização compulsória, a ciência da época norteou a classificação, patologização e segregação de jovens "abandonados" e "delinquentes" (BERnal, 2004). Como demonstra Chávez-García, as práticas científicas adotadas pelas instituições de reforma dos jovens californianos foram voltadas primordialmente às minorias raciais. Já no Brasil, ao analisar prontuários de jovens sob tutela do Serviço Social de Menores em São Paulo, Bernal (2004), não constatou haver tratamento diferenciado a brancos e negros. Todavia, a questão merece maior investigação. Nesse sentido, observa-se que, em relação a um período mais recente (1990-2006), Oliveira demonstra que a chance de adolescentes brancos serem sentenciados a uma medida privativa de liberdade é consideravelmente superior à de adolescentes negros (controladas outras variáveis), tanto no município quanto no estado de São Paulo. Portanto, assim como Chávez-García parte da situação atual de jovens negros e latinos nos Estados Unidos para conduzir uma pesquisa histórica sobre a justiça juvenil, é importante que pesquisadores brasileiros investiguem eventuais disparidades de tratamento racial nas práticas levadas a cabo durante a formação da justiça de jovens no país.

O Capítulo 5 da obra é dedicado à Escola Industrial de Preston. Seu foco principal reside nas práticas institucionais levadas a cabo na instituição desde o início de seu funcionamento, passando pela liderança de cerca de 25 anos de Otto Close, que dá nome ao capítulo, até os rumos da instituição após sua saída. Se as práticas de classificação, disciplina e, em alguns casos, esterilização foram responsáveis pelo sofrimento de diversos jovens institucionalizados na Whittier, a 
descrição da autora sobre a Preston revelam práticas ainda mais duras. A Preston, embora também tenha surgido como alternativa às criticadas práticas punitivas direcionadas a jovens, não passou de uma prisão para adolescentes.

Ao longo dos anos, inúmeros castigos físicos foram denunciados na Preston, como o uso de chicotes de nove tiras com nós nas pontas, colocação de sal nas feridas dos jovens e isolamento. Nesse sentido, o próprio Close descreveu seus funcionários como "negligentes" e "sádicos". Igualmente, outro diretor relatou o episódio em que sua esposa - que vivia com o marido na Preston - acordou horrorizada com os gritos e súplicas de jovens sendo chibatados. Uma das práticas que chama a atenção é a utilização de armas de fogo por alguns guardas, o que resultou na morte de um menino negro que tentou fugir da prisão.

Não obstante as péssimas condições da Preston em comparação à Whittier, um dos diretores que antecedeu Close buscou desenvolver um programa científico na instituição com a contratação de pesquisadores da Universidade de Berkeley. Contudo, dificuldades financeiras e inúmeras trocas de diretores fizeram com que a Preston não conseguisse estabelecer um programa semelhante ao da Whittier. A ineficácia da Escola na reforma de jovens era evidente: metade dos 250 jovens liberados pela Preston em 1929 por serem considerados exemplares tiveram como destino a prisão.

O cenário da Preston revela como os discursos de reforma da justiça juvenil e da necessidade de um tratamento especializado para a juventude não necessariamente se traduzem em práticas reabilitadoras. No Brasil, tanto as instituições que foram construídas para salvar os jovens no início do século XX (ALVAREZ, 1990), quanto muitas das regidas pelo Estatuto da Criança e do Adolescente de 1990 que prevê a proteção integral do jovem -, não deixaram de reproduzir práticas prisionais violentas (cf. SDH, 2012).

No Capítulo 6, Cháves-García retorna à Escola Whittier para discutir eventos que deram início à remodelação do sistema de justiça juvenil da Califórnia. A partir das mortes de dois jovens de ascendência mexicana em celas de confinamento solitário nos anos 1939 e 1940, uma série de investigações revelou as práticas brutais executadas na Whittier. Nos últimos anos do comando de Fred Nelles e após sua morte em 1927, o programa de reabilitação da Whittier foi praticamente extinto. Falta de recursos, incompetência dos diretores, apatia do público em relação aos reformatórios e o fechamento do centro de pesquisa fizeram com que a instituição se parecesse cada vez mais a uma prisão adulta.

Quando Benny Moreno foi encontrado com um cinto envolto no pescoço em uma cela de confinamento, onde estava por ter tentado fugir da instituição, a Whittier passou a ser alvo de interesse público. Sob pressão da comunidade mexicana 
da Califórnia, que viu nesse episódio mais um exemplo de discriminação racial, o governador do estado criou uma comissão para investigar o caso. Apesar de outros internos revelarem ter recebido cintos por parte dos funcionários sem uma explicação e de um deles ter ouvido um funcionário ameaçar Moreno, a comissão eximiu a instituição de qualquer responsabilidade na morte do jovem.

A morte de Edward Leiva no ano seguinte, no entanto, gerou investigações mais intensas. Assim como Moreno, Leiva foi encontrado morto em uma solitária. Seu suposto suicídio por asfixia com um lençol recebeu intensa cobertura midiática, com mais de 150 artigos do jornal Los Angeles Examiner sobre a Whittier. Ao entrevistar o pai de Leiva, o jornal revelou que ele sabia dos abusos sofridos pelo filho, que lhe havia relatado agressões físicas e sua colocação em uma cela solitária, onde passara um mês alimentando-se apenas de pão e água. Contudo, quando o pai do menino lhe anunciou que denunciaria a situação às autoridades, Leiva suplicou-lhe para que não o fizesse, com medo de retaliações.

Pressionado pelo público, mais uma vez o governador da Califórnia criou uma comissão para investigar a situação em Whittier. Nessa investigação, ao contrário da primeira, foram reveladas inúmeras violências praticadas dentro da instituição, inclusive com a conivência da direção. Um dos jovens ouvidos afirmou ter procurado o Superintendente para falar dos abusos sexuais praticados pelos guardas, tendo recebido como resposta que o próprio adolescente seria o culpado por tais ocorrências. Igualmente, a comissão constatou que eram comuns as agressões físicas. Entre as práticas violentas reveladas, estava a estratégia de obrigar jovens a sentarem em aquecedores elétricos até que confessassem infrações, e o espancamento e estupro coletivo de internos por seus companheiros. Em relação à morte de Leiva, a comissão concluiu que era fisicamente impossível o jovem ter se asfixiado. Todavia, apesar das evidências, o Diretor do Departamento de Instituições da Califórnia desmereceu os testemunhos, afirmando que provinham de pessoas "de inteligência subnormal, insanas, psicopatas ou criminosos".

Ao final da investigação, a comissão sugeriu reformas na instituição para que esta desenvolvesse um programa verdadeiramente reabilitador. Entre as medidas sugeridas, estavam a contratação de profissionais de diversas áreas, fim dos castigos corporais, melhor treinamento e remuneração dos funcionários e incentivo a esportes e a atividades religiosas. Para além de Whittier, uma das consequências das investigações foi a criação da Autoridade Juvenil, a qual seria encarregada de substituir o caráter retributivo da justiça juvenil por um caráter reabilitador, uma proposta semelhante à que impulsionou a própria criação das escolas em Whittier e em Preston. 
Em um momento em que o Brasil se encaminha para um endurecimento da punição de jovens, com o aumento do período de internação de adolescentes (BRASIL, 2015) e a diminuição da idade de responsabilização penal (BrASIL, 1993), é importante que se produzam pesquisas não apenas sobre a punição de jovens na atualidade, mas também nas suas origens. Desse modo, será possível colocar o presente em perspectiva, identificando-se descontinuidades, permanências e atualizações nos discursos e práticas sobre a punição de adolescentes. Sob essa perspectiva, a partir de Estados de Delinquência, é possível investigar como questões tais quais a preocupação com a juventude pobre, a utilização de saberes científicos, o uso de práticas de disciplina e de castigos brutais, cujos efeitos já são conhecidos, atualizam-se na atual conjuntura da punição de adolescentes.

\section{REFERÊNCIAS BIBLIOGRÁFICAS}

Alvarez, Marcos César. A Emergência do Código de Menores de 1927: Uma análise do discurso jurídico e institucional de assistência e proteção aos menores. Dissertação (Mestrado em Sociologia), Faculdade de Filosofia, Letras e Ciências Humanas, Universidade de São Paulo, São Paulo, 1990.

. Bacharéis, criminologistas e juristas: saber jurídico e nova escola penal no Brasil. São Paulo: Instituto Brasileiro de Ciências Criminais, 2003.

Bernal, Elaine Marina Bueno. Arquivos do abandono: experiências de crianças e adolescentes internados em instituições do Serviço Social de Menores de São Paulo (1938-1960). São Paulo: Cortez, 2004.

BRASIL. PROJETO DE EMENDA À CONSTITUIÇÃO N. 171, de 1993. Altera a redação do artigo 228 da Constituição Federal (imputabilidade penal do maior de dezesseis anos). Diário do Congresso Nacional, Brasília, Seção I, out. 1993. p. 23062-23064.

BRASIL. PROJETO DE LEI N. 333, de 2015 (do Senado Federal) PLS N. 333/2015. Altera o Dreceto-Lei $n^{0} 2.848$ de 7 de dezembro de 1940 (Código Penal) e as Leis no 8.069 de 13 de julho de 1990 (Estatuto da Criança e do Adolescente), e 12.594 de 18 de janeiro de 2012 (SINASE). Diário do Senado Federal, Brasília, 2 jun. 2015. p. 542-550.

Foucault, Michel. Vigiar e punir. Nascimento da prisão. 39ª ed. Petrópolis: Vozes, 2011. OliveIra, Thiago Rodrigues. Mecanismos sociais de decisões judiciais: um desenho misto explicativo sobre a aplicação da medida socioeducativa de internação. Dissertação (Mestrado em Sociologia), Faculdade de Filosofia, Letras e Ciências Humanas, Universidade de São Paulo, São Paulo, 2016.

SeCRETARIA DE Direitos humanos [SDH]. Atendimento Socioeducativo ao Adolescente em Conflito com a Lei. Levantamento Nacional 2011. Brasília, 2012. 